\title{
Controlling mechanical properties of bio-inspired hydrogels by modulating nano-scale, inter-polymeric junctions
}

\author{
Seonki Hong ${ }^{1}$, Hyukjin Lee ${ }^{2}$ and Haeshin Lee*1
}

\section{Full Research Paper}

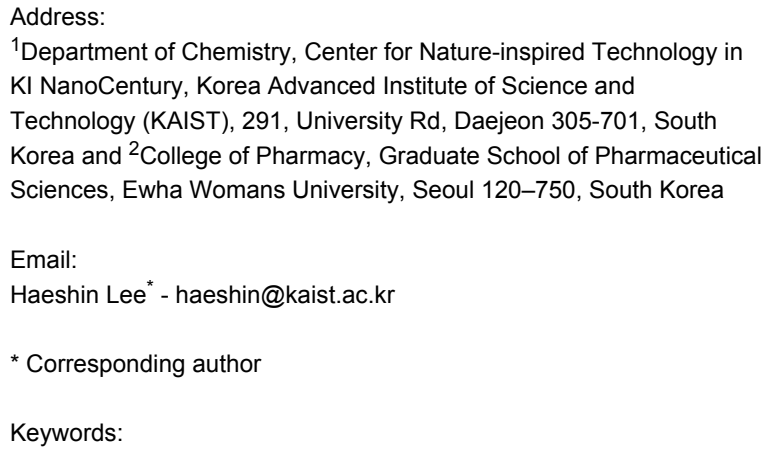

${ }^{1}$ Department of Chemistry, Center for Nature-inspired Technology in KI NanoCentury, Korea Advanced Institute of Science and Technology (KAIST), 291, University Rd, Daejeon 305-701, South Korea and ${ }^{2}$ College of Pharmacy, Graduate School of Pharmaceutical Sciences, Ewha Womans University, Seoul 120-750, South Korea

Email:

Haeshin Lee ${ }^{*}$ haeshin@kaist.ac.kr

* Corresponding author

Keywords:

catechols; hydrogels; poly(ethylene glycol)s; quinone tanning
Open Access

Beilstein J. Nanotechnol. 2014, 5, 887-894.

doi:10.3762/bjnano.5.101

Received: 22 November 2013

Accepted: 29 May 2014

Published: 23 June 2014

This article is part of the Thematic Series "Biological and bioinspired adhesion and friction".

Guest Editor: S. N. Gorb

(C) 2014 Hong et al; licensee Beilstein-Institut.

License and terms: see end of document.

\begin{abstract}
Quinone tanning is a well-characterized biochemical process found in invertebrates, which produce diverse materials from extremely hard tissues to soft water-resistant adhesives. Herein, we report new types of catecholamine PEG derivatives, PEG-NHcatechols that can utilize an expanded spectrum of catecholamine chemistry. The PEGs enable simultaneous participation of amine and catechol in quinone tanning crosslinking. The intermolecular reaction between PEG-NH-catechols forms a dramatic nano-scale junction resulting in enhancement of gelation kinetics and mechanical properties of PEG hydrogels compared to results obtained by using PEGs in the absence of amine groups. Therefore, the study provides new insight into designing new crosslinking chemistry for controlling nano-scale chemical reactions that can broaden unique properties of bulk hydrogels.
\end{abstract}

\section{Introduction}

Water-resistant adhesives secreted by marine mussels, stiff cuticles synthesized by insects, and sharp beaks found in squids appear to be drastically different biomaterials (Figure 1a-c) [1-6]. Not only their mechanical properties, but also their biological functions are distinct: The adhesives anchor mussels in place for survival and colonization, the cuticles securely protect insects from predators, pathogens, and environmental stresses, and the beaks act as a non-mineralized knife for capturing prey.
However, despite such differences in biological function, the molecular basis for the formation of the beaks, the cuticles, and the adhesives is similar. The process is called quinone tanning, which is defined by chemical crosslinking of proteins by a variety of reactive quinones. For mussel adhesives, DOPAquinone is formed by oxidation of a catecholic amino acid, 3,4dihydroxy-L-phenylalanine (DOPA). Subsequently, DOPAquinone rapidly reacts with basic amino acids, such as lysine 


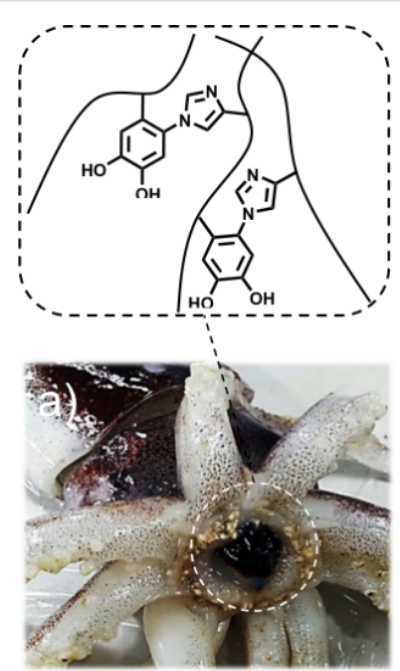

d)

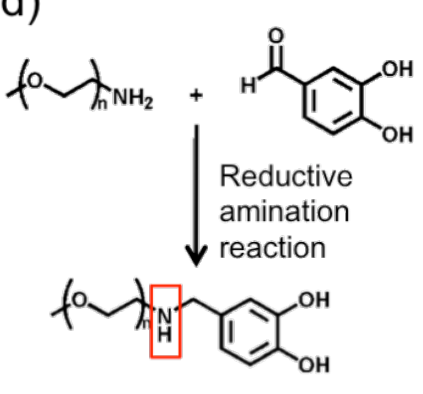

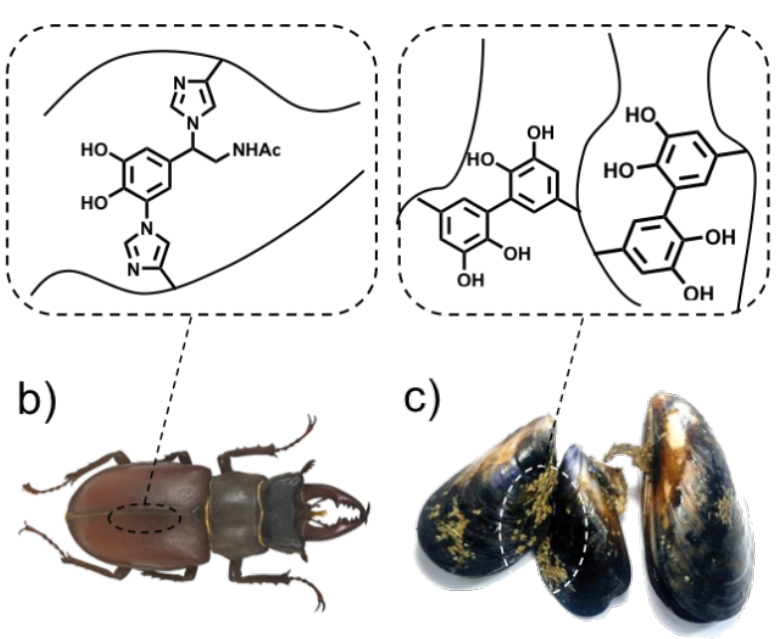

e)

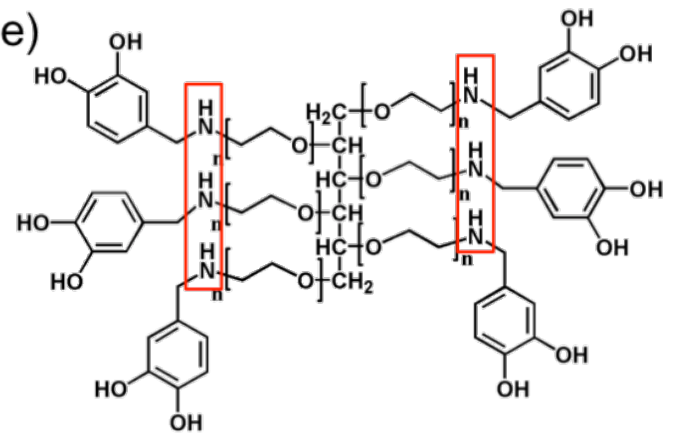

Figure 1: Biomaterials formed by quinone tanning processes found in (a) squid beaks, (b) insect cuticles, and (c) mussel adhesives. Representative chemical reactions were shown for each biomaterials (a,b,c top). Synthetic PEG derivatives that can mimic the natural catecholamine-involved quinone tanning due to the presence of secondary amine: (d) mPEG-NH-catechol for a model reaction, and (e) 6Arm-PEG-NH-catechol for hydrogels.

and/or histidine, forming covalent adducts of DOPA-DOPA, lysyl-DOPA, and/or histeinyl-DOPA [7-9]. For insect cuticles, the quinone tanning (i.e., sclerotization) occurs via crosslinking of cuticular proteins in which primary amines, secondary amines, and phenols from the proteins react with $\mathrm{N}$-acetylcatecholamines [9-11]. For squid beaks, the reaction between the imidazole of histidine and DOPAquinone is the primary mechanism for mechanical hardening of the beaks (Figure 1a-c) [6].

The quinone tanning process has been a useful method to create chemically functionalized interfaces regardless of the chemistry of materials. Recently, we and other research groups have reported novel strategies for the functionalization of virtually any material surfaces by using synthetic catecholamine polymers such as poly(dopamine) [12], poly(norepinephrine) [13], and poly(ethylenimine)-catechol [14]. The surfaces modified by those catecholamines exhibited a variety of functionalities such as protein-immobilization [15], facilitating cell adhesion [16], attenuating in vivo toxicity [17], initiating bio-mineralization [18], graphene nano-composites [19], and bio-inspired adhesives $[20,21]$. In addition to the interface science and engi- neering, methods to prepare bulk materials such as poly(ethylene glycol) (PEG) and pluronic hydrogels have been reported [22-26]. However, most previous work utilized catechol-catechol crosslinking by using catechol end-functionalized polymers, which limits the control of important variables in hydrogels such as gelation kinetics and mechanical properties.

Herein, we report new types of PEG derivatives (linear mPEGNH-catechol and branched 6Arm-PEG-NH-catechol) that offer an expanded spectrum of catecholamine chemistry. In the PEG derivatives, catechol and secondary amine coexist that can effectively mimic the chemical process of catecholamineinvolved quinone tanning. The hydrogels produced by catecholamine crosslinking using 6Arm-PEG-NH-catechol exhibited enhanced mechanical properties and rapid gelation compared to the hydrogel prepared by PEGs that can only use catechol-catechol crosslinking. This study demonstrates that the chemical configuration by inserting both secondary amine and catechol expands the properties of PEG hydrogels, which can provide new insight into designing hydrogels prepared by other polymers using quinone tanning chemistry. 


\section{Results and Discussion Quinone tanning reactions of catecholamine PEGs}

Preparation of linear $(5 \mathrm{kDa})$ and 6Arm-PEG-NH-catechol $(15 \mathrm{kDa})$ was performed by a simple one-step reductive amination between 3,4-dihydroxybenzaldehyde (DHBA) and linear or 6Arm-PEG-NH ${ }_{2}$ (Figure $1 \mathrm{~d}$ and Figure 1e). Primary amines are difficult to be chemically tethered to PEG-catechol, because the typical reaction (i.e., EDC coupling) is the formation of an amide bond between the primary amine and the carboxyl group. Instead, we could easily generate secondary amines by using aldehyde chemistry, in other words reductive amination reaction, for the PEG-catechol to contain secondary amine groups. Secondary amines are also well-known to be reactive with catechol, which has been found in natural organisms [6]. The product was purified by dialysis ( $\mathrm{MWCO}=3 \mathrm{kDa}$ for linear PEG and $\mathrm{MWCO}=10 \mathrm{kDa}$ for 6Arm-PEG) for two days and was subsequently lyophilized. White powders were obtained for both PEG derivatives. An absolute negative result from the ninhydrin test indicated that all amine groups of linear and 6Arm-PEGs had reacted with the catechol derivatives. Control polymers with the absence of secondary amines, linear and 6Arm-PEG-catechols, were prepared by an amide bond forming reaction using the BOP/HOBt/DIPEA coupling with 3,4-dihydroxyhydrocinnamic acid (DHCA) and linear or 6Arm-PEG$\mathrm{NH}_{2}$.

To investigate the effect of secondary amines on the results of quinone tanning, both linear PEG derivatives, mPEG-NH-catechol and mPEG-catechol, underwent the same crosslinking reactions in phosphate buffered saline $(\mathrm{pH} 8.0$ with $0.3 \mathrm{mM}$ $\mathrm{NaIO}_{4}$ ) (Supporting Information File 1, Figure S6). Quantitative analysis of the crosslinked PEG products was performed by gel permeation chromatography (GPC). GPC results showed that the peak that appeared at $18 \mathrm{~min}$ of elution time is unreacted monomer (Standard data of unreacted monomer: Supporting Information File 1, Figure S5), and the other peaks eluted at around $17 \mathrm{~min}$ or earlier indicate multimers resulting from the quinone tanning reactions. The peak intensities of the multimers and the monomer were varied depending on the concentration of $\mathrm{NaIO}_{4}$, which initiated the quinone tanning reaction. It was found that maximum intensity of the multimer peaks was obtained at 1.5 equiv $\mathrm{NaIO}_{4}$ to catechols for both mPEG-NH-catechol (Supporting Information File 1, Figure S6, left) and mPEG-catechol (Supporting Information File 1, Figure $\mathrm{S} 6$, right). The entire range of $\mathrm{NaIO}_{4}$ added to the reaction mixtures was $0.25-2$ equiv to catechols. Amounts of $\mathrm{NaIO}_{4}$ higher than 1.5 equiv no longer affected the results of the crosslinking. In fact, the intensity of the multimer peak for mPEG-NH-catechol was decreased, when 2 equiv of $\mathrm{NaIO}_{4}$ were used. One equivalent of $\mathrm{NaIO}_{4}$ to catechol is enough, but in practice a slight excess of $\mathrm{NaIO}_{4}$ was found to be necessary for maximal crosslinking.

\section{Quantitative analysis of crosslinked PEG products with GPC}

One notable result was that the relative amounts and the molecular species of the multimers formed by quinone tanning reactions exhibited large differences between mPEG-NH-catechol and mPEG-catechol. For mPEG-NH-catechol, multimers were a major component (Figure 2a) but became a minor molecular species for mPEG-catechol. The monomer was dominant in the mPEG-catechol reaction mixture (Figure $2 b$ ).

a)
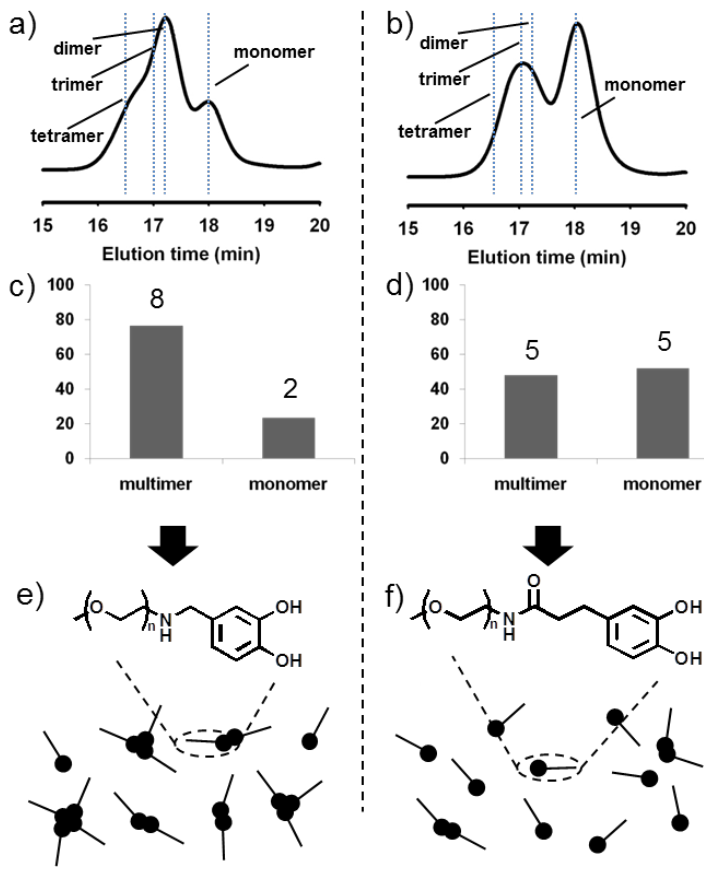

d) 100

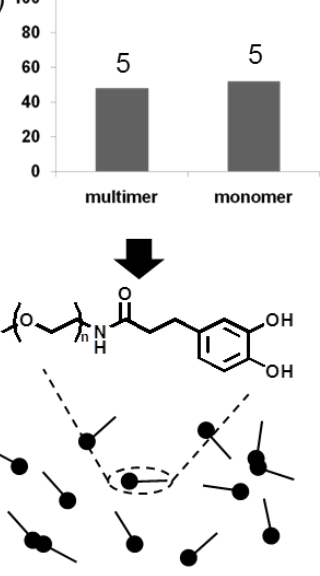

Figure 2: Comparative analysis of crosslinking products of $\mathrm{mPEG}-\mathrm{NH}$ catechol and mPEG-catechol. (a,b) GPC data obtained from crosslinking at a stoichiometric ratio of $\mathrm{NaIO}_{4}$ : catechol $=1.5: 1$. The dot lines indicate each elution time of PEG standards with molecular weight of $5,10,15$, and $20 \mathrm{kDa}$. The quantitative multimeric and monomeric ratio of crosslinked mPEG-NH-catechol and mPEG-catechol were shown in (c) and (d). (e,f) Schematic results comparing nanoscale junctions formed by (e) mPEG-NH-catechol and (f) mPEGcatechol.

The molecular weight analysis of the GPC products showed that the multimer peak consisted of dimeric, trimeric, and tetrameric PEGs, composing up to about 80 percent of the total product in the $\mathrm{mPEG}-\mathrm{NH}$-catechol reaction mixture (Figure 2c). However, for mPEG-catechol, the GPC analysis showed that only dimeric and trimeric PEGs was formed. No indication of tetramers was found in the reaction mixture, and a large amount of unreacted monomer, about 50 percent, remained (Figure 2d). The lines in 
Figure $2 \mathrm{a}$ and Figure $2 \mathrm{~b}$ indicate the elution time of standard PEG compounds with known molecular weight and configuration. Linear mPEG-NH $5 \mathrm{kDa}$ (18.0 min elution time), 10 $\mathrm{kDa}$ (17.2 min), 4Arm-PEG-NH $20 \mathrm{kDa}(16.5 \mathrm{~min})$ were used as standards (Supporting Information File 1, Figure S5). These results demonstrated that the quinone tanning reaction involved with amine and catechol simultaneously was more efficient than the reaction engaged only with catechol (Figure $2 \mathrm{e}$ and $2 \mathrm{f}$ ). This result strongly suggests that one can control physicochemical properties of a wide variety of PEG-containing biomaterials by designing effective conjugation chemistry. We chose PEG hydrogels as an example.

\section{Effect of the amine group in PEG gelation I: mechanical properties of hydrogels}

To explore the effect of the amine group in PEG gelation, we prepared 6Arm-PEG-NH-catechol and 6Arm-PEG-catechol (control). Both were dissolved in PBS pH 8.0 with a final concentration of $3 \%(\mathrm{w} / \mathrm{v})$. It is expected that the hydrogel formed by amine-catechol involved tanning (6Arm-PEG-NHcatechol) may exhibit faster gelation kinetics and stronger mechanical properties than the one formed by a catechol-catechol tanning (6Arm-PEG-catechol). We measured the mechanical modulus of the hydrogels by a rheometer. Frequency $(0.01$ to $10 \mathrm{~Hz}$, Figure $3 \mathrm{a}$ ) and strain (1 to $90 \%$, Figure $3 \mathrm{~b}$ ) sweeps were performed for three times each on both 6Arm-PEG-NHcatechol and 6Arm-PEG-catechol hydrogels, after allowing time for complete gelation (10 min). The elastic modulus, G', and loss modulus, G", were found to be independent over a wide range of frequencies and strains, demonstrating that the gelation was successfully completed within $10 \mathrm{~min}$. The elastic modulus of the hydrogel made of 6Arm-PEG-NH-catechol was about 1,000 $\mathrm{Pa}$, but the G' of the hydrogel prepared by 6ArmPEG-catechol was low, as expected (about $500 \mathrm{~Pa}$ ). The twotimes increase in the elastic modulus indicates that amine-catechol quinone tanning is more chemically efficient process compared to catechol-catechol tanning. Therefore, we understand that the amine-catechol tanning process has been chosen in nature to produce stiff biomaterials for the various invertebrates shown in Figure 1.

\section{Effect of the amine group in PEG gelation II: differences in gelation kinetics}

In rheology, gelation point is defined by the intersection of the elastic modulus (G') and the loss modulus (G”). We tried to measure the point by a rheometer, but it was found that gelation occurred within a minute in both hydrogels (6Arm-PEGNH-catechol and 6Arm-PEG-catechol), preventing a direct measurement of the gelation time in a rheometer. There was, however, a difference in gelation kinetics: dropping the solu-

\section{a)}

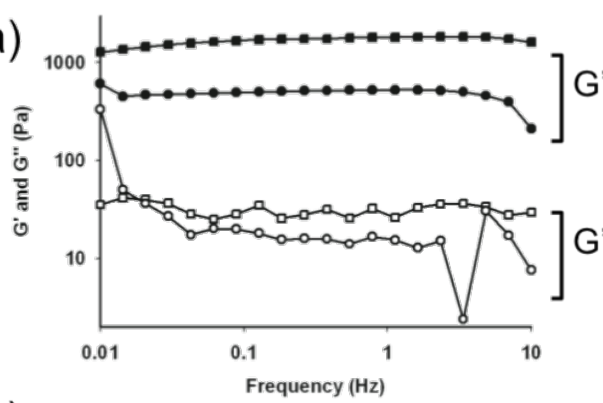

b)

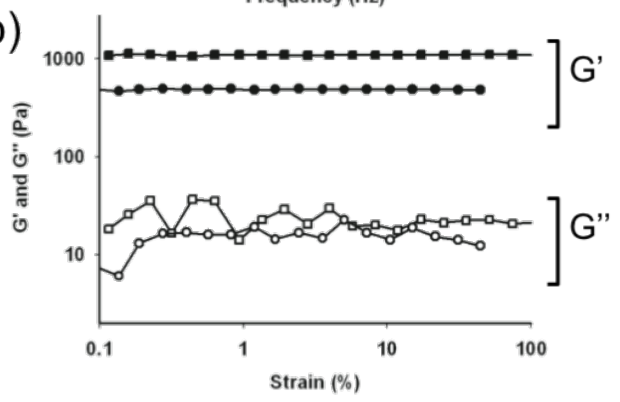

c)

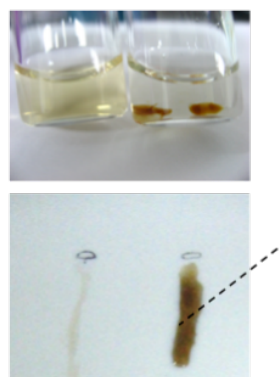

6Arm PEG$\mathrm{NH}$-catechol
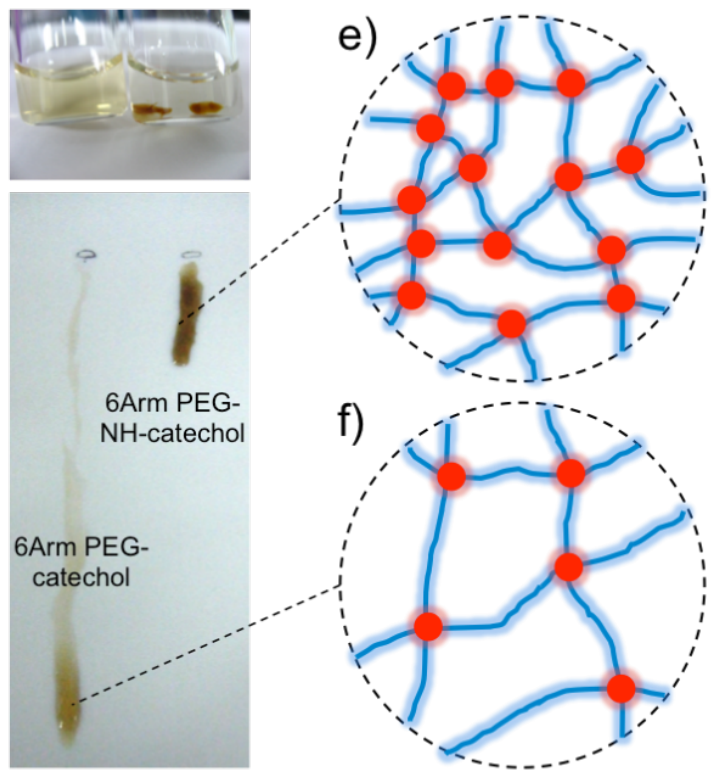

Figure 3: Rheological analysis data of quinone tanning inspired crosslinking hydrogels (a) frequency sweep and (b) strain sweep of 6Arm-PEG-NHcatechol (square) and 6Arm-PEG-catechol (circle). ( $n=3$ each) (c) Rapid quinone tanning of 6Arm-PEG-NH-catechol (right) in NalO 4 (100 mM in DDW). A visible tanning reaction was not observed in 6 Arm-PEG-catechol (left). (d) Measurement of gelation kinetics by dropping solutions of 6 ArmPEG-NH-catechol (right) and 6Arm-PEG-catechol (left) on a PTFE surface (45 deg slope). (e and f) Schematic results showing nano-scale junctions formed by (e) 6Arm-PEG-NH-catechol and (f) 6Arm-PEG-catechol. 
tion of 6 Arm-PEG-NH-catechol $\left(3 \%\right.$ w/v) into a $\mathrm{NaIO}_{4}$ solution (100 $\mathrm{mM}$ in DDW) immediately formed dark brown gellike aggregates (Figure 3c, right bottle). In contrast, such rapid aggregates were not detected when dropping the 6Arm-PEGcatechol solution was dropped into the same solution (Figure 3c, left bottle). The PEG solution was dispersed in the $\mathrm{NaIO}_{4}$ solution. This clear indication of differences in the gelation time led us to design a new, simple method for measuring this parameter. A poly(tetrafluoroethylene) (PTFE) surface was set up at a $45^{\circ}$ slope angle, and drops of 6Arm-PEG-NH-catechol (Figure 3d, right) and 6Arm-PEG-catechol (Figure 3d, left) solutions were applied to observe the gelation time. The PEG solution flowed in the liquid phase but stopped in the gel phase. Immediate gelation of 6Arm-PEG-NH-catechol was observed within $2 \mathrm{~s}$, but it took about $12 \mathrm{~s}$ for the 6Arm-PEG-catechol solution to become a hydrogel. This result, combined with the rheology data, indicates that amine-catechol tanning is an efficient process that is suitable for controlling a large number of chemical junctions in nanobiomaterials (Figure $3 \mathrm{e}$ and Figure $3 \mathrm{f}$ ). Because the reaction occurs in aqueous conditions, many invertebrates utilize this process to produce a variety of biomaterials for their use in nature. The effective tanning process of catechol and amine demonstrated herein suggests a general approach for creating novel catecholaminergic derivatives of biopolymers such as alginate, hyaluronic acid, chitosan, dextran, and other synthetic or proteineous materials for a variety of applications.

Quinone, an oxidized form of catechol, is reactive to nucleophiles such as hydroxyl, amine, and quinone, which typically undergo the 1,4-Michael addition reactions [27]. Considering the molecular structures of PEGs studied herein, three quinone tanning reactions are possible: (i) catechol-catechol formation through $\mathrm{C}-\mathrm{C}$ coupling between phenyl rings $[27,28]$, (ii) $\mathrm{C}-\mathrm{O}$ coupling at a $\mathrm{C}-4$ position by the reaction between deprotonated hydroxyl anion and quinone [27,29], and (iii) $\mathrm{C}-\mathrm{N}$ coupling at the same position by the secondary amine and quinone [7-11,27]. For PEG-catechol, the $\mathrm{C}-\mathrm{C}$ and $\mathrm{C}-\mathrm{O}$ couplings are the only possible quinone tanning mechanisms to form hydrogels (Figure 4a). However, for PEG-NH-catechol, another scenario of $\mathrm{C}-\mathrm{N}$ coupling is added to the two previous tanning reactions (catechol-catechol and $\mathrm{C}-\mathrm{O}$ couplings of

\section{a) Quinone tanning of catechol}<smiles>[Y]c1ccc(Oc2cc(O)c(O)cc2[Y])c(O)c1</smiles>

Hydroxylation<smiles>[Y][Y]([H])(C)c1cc(O)c(O)cc1-c1cc(O)c(O)cc1C(C)(C)C</smiles>

Dimerization

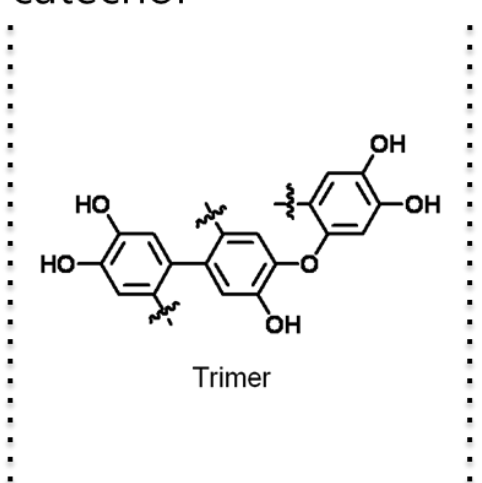

b) Quinone tanning of catecholamine<smiles></smiles>

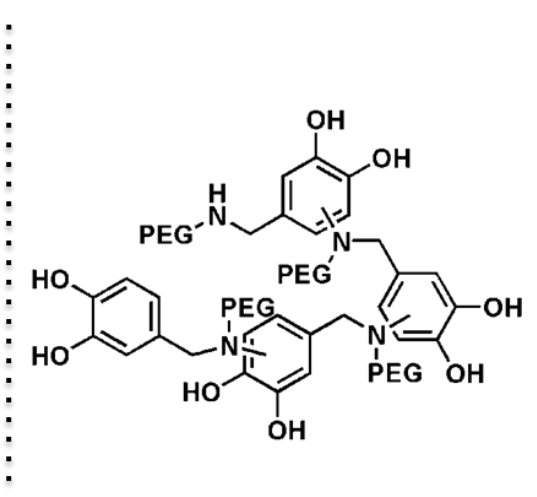


PEG-catechol) (Figure 4b). It is generally accepted that the nucleophilicity of amines is higher than that of a hydroxyl group. Thus, nature utilizes the amine-involved quinone tanning reactions for the formation of stiff insect cuticles [7-11,27] by a reaction between imidazole (side-chain of histidine) and catechol. So far, the majority of research was focused on catechol-catechol crosslinking [25,30,31], accidentally ignoring the importance of catecholamine quinone tanning. Thus, the results demonstrated herein can be a useful toolkit to further control physicochemical properties of biomaterials.

\section{Conclusion}

In summary, we demonstrated that the particular quinone tanning process simultaneously involved with catechol and amine was effective in crosslinking. The linear type of polymer mPEG-NH-catechol showed superior crosslinking result compared to mPEG-catechol, the polymer crosslinked via catechol-catechol tanning. Similar to the difference in crosslinking efficiency in linear PEG experiments, hydrogels formed by multi-armed PEGs showed that the hydrogel utilizing catechol-amine tanning, 6Arm-PEG-NH-catechol, showed fast in gelation kinetics (about $2 \mathrm{~s}$ ) and strong in mechanical properties $\left(\mathrm{G}^{\prime}>1,000 \mathrm{~Pa}\right)$ compared to the hydrogel produced by 6Arm-PEG-catechol (about $12 \mathrm{~s}$ and about $500 \mathrm{~Pa}$ ).

\section{Experimental \\ Materials}

6Arm-PEG-amine (PEG- $\left.\left(\mathrm{NH}_{2}\right)_{4}, M_{\mathrm{w}}=15,000 \mathrm{Da}\right)$ and methoxy-PEG-amine (mPEG-NH $\left.2, M_{\mathrm{w}}=5,000 \mathrm{Da}\right)$ were purchased from SunBio, Inc. (Walnut Creek, CA). Sodium periodate $\left(\mathrm{NaIO}_{4}\right)$, sodium cyanoborohydride $\left(\mathrm{NaBH}_{3} \mathrm{CN}\right), N, N$ diisopropylethylamine (DIPEA), 3,4-dihydroxyhydrocinnamic acid (DHCA) and 3,4-dihydroxybenzaldehyde (DHBA) were acquired from Sigma-Aldrich (St. Louis, MO). 1-Hydroxybenzotriazole (HOBt) hydrate was purchased from Peptides International (Louisville, KY) and benzotriazole-1-yl-oxy-tris-(dimethylamino)-phosphonium hexafluorophosphate (BOP) was acquired from Novabiochem (Germany).

\section{Synthesis of catechol-conjugated PEG (1)}

Synthesis of 6Arm-PEG-catechol and mPEG-catechol: 6ArmPEG-amine ( $1 \mathrm{~g}, 0.067 \mathrm{mmol})$ was dissolved in $10 \mathrm{~mL}$ of NMP at $60{ }^{\circ} \mathrm{C}$ for $10 \mathrm{~min}$. DHCA $(0.8 \mathrm{mmol})$, BOP $(0.8 \mathrm{mmol})$, HOBt $(0.8 \mathrm{mmol})$ and DIPEA $(0.8 \mathrm{mmol})$ were dissolved in $5 \mathrm{~mL}$ of NMP in a separate vial. The PEG and DHCA solutions were mixed and reacted at room temperature for 3-6 h. The reaction solution was purified by dialysis at acidic condition for $2 \mathrm{~d}$ and then lyophilized. (Dialysis conditions: $10 \mathrm{~mL}$ of polymer solution was added to $3 \mathrm{~L}$ of DDW for $3 \mathrm{~h}$ and the dialysate was exchanged for four times. $\mathrm{MWCO}=5,000$.) The content of catechol was confirmed by UV-vis spectroscopy at
$280 \mathrm{~nm}$. The UV-vis intensity of catechol modified polymer was calculated to the contents of catechol by using the standard curve made by the known concentration of dopamine solution versus the UV-vis intensity, demonstrating that all terminal amine groups were conjugated with DHCA. The catechol contents of catechol-modified PEG were double checked by the ninhydrin test. The ninhydrin test was performed by mixing $20 \mu \mathrm{L}$ of catechol-modified PEG $\left(1 \mathrm{mg} \mathrm{mL}^{-1}\right.$ in DDW) with $20 \mu \mathrm{L}$ of $2 \%$ ninhydrin reagent solution, followed by heating at $100{ }^{\circ} \mathrm{C}$ for $3 \mathrm{~min}$. The heated solution was diluted to $700 \mu \mathrm{L}$ of DDW and then the primary amine and secondary amine was confirmed by UV-vis spectrometer at $470 \mathrm{~nm}$ and $440 \mathrm{~nm}$. $\left.{ }^{1} \mathrm{H} \mathrm{NMR} \mathrm{(300} \mathrm{MHz,} \mathrm{CDCl}_{3}, \delta\right): 6.71-6.69(\mathrm{~m}, 2 \mathrm{H}$, $\left.\mathrm{C}_{6} \mathrm{HH}_{2}(\mathrm{OH})_{2-}^{-}\right), 6.52-6.49$ (dd, $\left.1 \mathrm{H}, \mathrm{C}_{6} \mathrm{H}_{2} \mathrm{H}(\mathrm{OH})_{2}-\right)$, 3.79-3.33 (m, PEO), 2.81-2.76 (t, 2H, $\mathrm{C}_{6} \mathrm{H}_{3}(\mathrm{OH})_{2}-\mathrm{CH}_{2}-$ ), 2.49-2.44 (t, $\left.2 \mathrm{H}, \mathrm{CH}_{2}-\mathrm{C}(\mathrm{O}) \mathrm{NH}-\right)$. mPEG-catechol was prepared by using the same procedure described above with the amount of reagents used are the followings: mPEG-amine $(200 \mathrm{mg}, 0.04 \mathrm{mmol})$, DHCA (0.048 mmol), BOP (0.048 mmol), HOBt (0.048 mmol) and DIPEA (0.048 mmol). The Purity of synthetic PEGs was determined by ${ }^{1} \mathrm{H}$ NMR and GPC (Supporting Information File 1, Figure S2 and S4).

\section{Synthesis of catechol-conjugated PEG (2)}

6Arm-PEG-amine (200 mg, $0.013 \mathrm{mmol}$ ) was solved in $2 \mathrm{~mL}$ of $\mathrm{NMP}$ at $60{ }^{\circ} \mathrm{C}$ for $10 \mathrm{~min}$. DHBA (33 mg, $0.24 \mathrm{mmol}$ ) in $1 \mathrm{~mL}$ of NMP was added to the PEG solution and stirred at room temperature for $1 \mathrm{~h}$. $\mathrm{NaBH}_{3} \mathrm{CN}$ (38 mg, $0.6 \mathrm{mmol}$ ) in $100 \mu \mathrm{L}$ of NMP was added to that solution and reacted at room temperature for overnight. The reaction solution was successively purified by dialysis at acidic condition for $2 \mathrm{~d}$ and then lyophilized. The content of catechol was confirmed by ultraviolet-visible spectroscopy at $280 \mathrm{~nm}$, demonstrating that all terminal amine groups were conjugated with DHBA. (The dialysis condition and catechol content assay were the same as in the synthesis of 6Arm-PEG-catechol and mPEG-catechol.) ${ }^{1} \mathrm{H}$ NMR (300 MHz, $\left.\mathrm{CDCl}_{3}, \delta\right) 7.19\left(\mathrm{~s}, 1 \mathrm{H}, \mathrm{C}_{6} \mathrm{H}_{2} \mathrm{H}(\mathrm{OH})_{2}-\right), 6.81-6.88(\mathrm{~m}, 2 \mathrm{H}$, $\left.\mathrm{C}_{6} \mathrm{HH}_{2}-(\mathrm{OH})_{2}-\right), 4.09-4.05\left(\mathrm{~m}, 2 \mathrm{H},-\mathrm{NH}-\mathrm{CH}_{2}-\mathrm{C}_{6} \mathrm{H}_{3}(\mathrm{OH})_{2}-\right)$, 3.95-3.59 (m, PEO), 3.40-3.36 (t, 2H, PEO-CH $2-\mathrm{NH}-$ ). mPEG$\mathrm{NH}$-catechol was prepared by using the same procedure described above with the amount of reagents used being as follows: mPEG-amine (200 mg, $0.04 \mathrm{mmol})$, DHBA (17 mg, $0.12 \mathrm{mmol}$ ), $\mathrm{NaBH}_{3} \mathrm{CN}$ (38 mg, $0.6 \mathrm{mmol}$ ). The purity of synthetic PEGs was determined by ${ }^{1} \mathrm{H}$ NMR and GPC (Supporting Information File 1, Figure S1 and S3).

\section{Quinone tanning reactions of catecholamine PEGs}

Quinone tanning reactions of mPEG-NH-catechol and mPEGcatechol were performed by the addition of sodium periodate $\left(\mathrm{NaIO}_{4}\right)$ to PEG solutions $\left(2 \mathrm{mg} \mathrm{mL}^{-1}\right.$ in $10 \mathrm{mM}$ phosphate 
buffered saline, $\mathrm{pH} 8.5$ ), and the resulting molecular weight of the crosslinked PEGs was determined by gel permeation chromatography (GPC). Two GPC columns (OHpak SB-806M HQ and SB-804 HQ, Shodex ${ }^{\circledR}$, Munich, Germany) were connected in series and equilibrated with phosphate buffered saline (10 mM, pH 4.0). The detector for the PEG standard was a reflective index detector (Shodex, RI-71), and a UV-vis spectrometer (Hewlett Packard HP 8453 spectrophotometer, $190 \mathrm{~nm}$ to $1100 \mathrm{~nm}$, integration time $0.5 \mathrm{sec}$, interval $1 \mathrm{~nm}$, Deuterium lamp for UV and tungsten lamp for vis) was used for detecting the catechol modified polymers. The columns were characterized with various PEG standards: mPEG-amine (linear, $5 \mathrm{kDa}$ ), mPEG-amine (linear, $10 \mathrm{kDa}$ ), 4Arm-PEG-amine (star shaped, $20 \mathrm{kDa}$ ). The elution time of the PEG standards were $18 \mathrm{~min}$ for mPEG-NH $\mathrm{N}_{2}$ (linear, $5 \mathrm{kDa}$ ), 17.2 min for mPEG-amine (linear, $10 \mathrm{kDa}$ ), $16.5 \mathrm{~min}$ for 4Arm-PEG-NH 2 (star shaped, $20 \mathrm{kDa}$ ). Our GPC column approximately separated the 100 Da molecular weight after 30 min elution time, calculated by using a standard curve of $130 \mathrm{kDa}, 30 \mathrm{kDa}, 20 \mathrm{kDa}$, and $5 \mathrm{kDa}$ molecular weight hyaluronic acid and PEGs. (Supporting Information File 1, Figure S5) The quinone tanning reaction was optimized by varying the amount of sodium periodate ( 0.1 to 2 equiv relative to mole of catechol). It was confirmed in our previous report that the chemical pathway of catechol crosslinking is exactly the same whether $\mathrm{NaIO}_{4}$ is used or not, and $\mathrm{NaIO}_{4}$ can effectively control the kinetics of catecholamine crosslinking without any additional byproducts [32].

\section{Formation of PEG hydrogels}

To form PEG hydrogels, 1.5 equiv of $\mathrm{NaIO}_{4}$ (moles of catechol basis) was added to $3 \%$ PEG solution $\left(30 \mathrm{mg} \mathrm{mL}^{-1}\right.$ in phosphate-buffered saline, $\mathrm{pH} 8.0$ ), and the subsequently determined gelation time through vial inversion method was typically $10-20 \mathrm{~s}$. For a naccurate determination of the gelation time, we used PTFE plate setup with 45 degree slope and droplets of PEG solutions $(10 \mu \mathrm{L})$ allowed to flow until the solutions stopped when became hydrogels.

\section{Oscillatory rheometry}

Oscillatory rheometry by using a rotating rheometer (Bohlin Advanced Rheometer with a parallel $20 \mathrm{~mm}$ plate, Malvern Instruments, UK) was used to determine the mechanical properties of the PEG hydrogels. Strain sweep was performed at $1 \mathrm{~Hz}$ and frequency sweep was carried out at a strain of $10 \%$ after $10 \mathrm{~min}$ from the gel formed. To perform rheology studies of the modified-PEG hydrogels, 1.5 equiv of $\mathrm{NaIO}_{4}$ (moles of catechol basis) was added to $3 \%$ PEG solution $\left(30 \mathrm{mg} \mathrm{mL}^{-1}\right.$ in phosphate-buffered saline, $\mathrm{pH}$ 8.0) in 24 well-plate as a mold for rheology sample. The formed hydrogel was a cylinder shape with diameter of $16 \mathrm{~mm}$ and height of $1 \mathrm{~mm}$. The time dependent rheology test showed that the sol-gel transition was finished within $1 \mathrm{~min}$ (data not shown). In order to test the mechanical properties of the hydrogels in a stable condition, we carried out the frequency and strain sweep test $10 \mathrm{~min}$ after the gel formed.

\section{Supporting Information}

\section{Supporting Information File 1}

Further experimental data.

The further experimental data describes ${ }^{1} \mathrm{H}$ NMR and GPC

data for the purity of synthetic products, $\mathrm{mPEG}$-catechol,

mPEG-NH-catechol, 6Arm-PEG-catechol, and

6Arm-PEG-NH-catechol.

[http://www.beilstein-journals.org/bjnano/content/

supplementary/2190-4286-5-101-S1.pdf]

\section{Acknowledgements}

The authors are grateful to the financial support from National Research Foundation: Mid-career Scientist Grant (2104002855) and Biomedical Technology Development Program (20120006085). World Premier Material (WPM) Program from the Ministry of Knowledge and Economy. This work is also supported in part by Development of Future Therapeutic Materials Program (A120170) from The Ministry of Health and Welfare.

\section{References}

1. Waite, J. H.; Andersen, N. H.; Jewhurst, S.; Sun, C. J. J. Adhes. 2005, 81, 297. doi:10.1080/00218460590944602

2. Deming, T. J. Curr. Opin. Chem. Biol. 1999, 3, 100. doi:10.1016/S1367-5931(99)80018-0

3. Waite, J. H.; Tanzer, M. L. Science 1981, 212, 1038. doi:10.1126/science. 212.4498 .1038

4. Sherald, A. F. Experientia 1980, 36, 143. doi:10.1007/BF01953696

5. Andersen, S. O. Insect Biochem. Mol. Biol. 2010, 40, 166. doi:10.1016/j.ibmb.2009.10.007

6. Miserez, A.; Schneberk, T.; Sun, C. J.; Zok, F. W.; Waite, J. H. Science 2008, 319, 1816. doi:10.1126/science.1154117

7. Waite, J. H. Integr. Comp. Biol. 2002, 42, 1172. doi:10.1093/icb/42.6.1172

8. Bittner, S. Amino Acids 2006, 30, 205. doi:10.1007/s00726-005-0298-2

9. Kramer, K. J.; Kanost, M. R.; Hopkins, T. L.; Jiang, H. B.; Zhu, Y. C.; Xu, R. D.; Kerwin, J. L.; Turecek, F. Tetrahedron 2001, 57, 385. doi:10.1016/S0040-4020(00)00949-2

10. Suderman, R. J.; Dittmer, N. T.; Kramer, K. J.; Kanost, M. R. Insect Biochem. Mol. Biol. 2010, 40, 252. doi:10.1016/j.ibmb.2010.02.008

11. Kerwin, J. L.; Turecek, F.; Xu, R. D.; Kramer, K. J.; Hopkins, T. L.; Gatlin, C. L.; Yates, J. R., III. Anal. Biochem. 1999, 268, 229. doi:10.1006/abio.1998.3069

12. Lee, H.; Dellatore, S. M.; Miller, W. M.; Messersmith, P. B. Science 2007, 318, 426. doi:10.1126/science.1147241

13. Kang, S. M.; Rho, J.; Choi, I. S.; Messersmith, P. B.; Lee, H. J. Am. Chem. Soc. 2009, 131, 13224. doi:10.1021/ja905183k 
14. Lee, H.; Lee, Y.; Statz, A. R.; Rho, J.; Park, T. G.; Messersmith, P. B. Adv. Mater. 2008, 20, 1619. doi:10.1002/adma.200702378

15. Lee, H.; Rho, J.; Messersmith, P. B. Adv. Mater. 2009, 21, 431. doi:10.1002/adma.200801222

16. Ku, S. H.; Ryu, J.; Hong, S. K.; Lee, H.; Park, C. B. Biomaterials 2010, 31, 2535. doi:10.1016/j.biomaterials.2009.12.020

17. Hong, S.; Kim, K. Y.; Hwang, J. W.; Park, S. Y.; Lee, K. D.; Lee, D. Y.; Lee, H. Nanomedicine 2011, 6, 793. doi:10.2217/nnm.11.76

18. Ryu, J.; Ku, S. H.; Lee, H.; Park, C. B. Adv. Funct. Mater. 2010, 20 , 2132. doi:10.1002/adfm.200902347

19. Kang, S. M.; Park, S.; Kim, D.; Ruoff, R. S.; Lee, H. Adv. Funct. Mater. 2010, 21, 108. doi:10.1002/adfm.201001692

20. Kaneko, D.; Kinugawa, S.; Matsumoto, K.; Kaneko, T. Plant Biotechnol. (Tokyo, Jpn.) 2010, 27, 293. doi:10.5511/plantbiotechnology.27.293

21. Kaneko, D.; Wang, S.; Matsumoto, K.; Kinugawa, S.; Yasaki, K.; Chi, D. H.; Kaneko, T. Polym. J. 2011, 43, 855. doi:10.1038/pj.2011.77

22. Huang, K.; Lee, B. P.; Ingram, D. R.; Messersmith, P. B. Biomacromolecules 2002, 3, 397. doi:10.1021/bm015650p

23. Lee, B. P.; Dalsin, J. L.; Messersmith, P. B. Biomacromolecules 2002, 3, 1038. doi:10.1021/bm025546n

24. Westwood, G.; Horton, T. N.; Wilker, J. J. Macromolecules 2007, 40, 3960. doi:10.1021/ma0703002

25. Lee, B. P.; Chao, C. Y.; Nunalee, F. N.; Motan, E.; Shull, K. R.; Messersmith, P. B. Macromolecules 2006, 39, 1740. doi: $10.1021 / \mathrm{ma} 0518959$

26. Brubaker, C. E.; Kissler, H.; Wang, L. J.; Kaufman, D. B.; Messersmith, P. B. Biomaterials 2010, 31, 420. doi:10.1016/j.biomaterials.2009.09.062

27. Nematollahi, D.; Tammari, E.; Sharifi, S.; Kazemi, M. Electrochim. Acta 2004, 49, 591. doi:10.1016/j.electacta.2003.09.013

28. Rayn, M. D.; Yueh, A.; Wen-Yu, C. J. Electrochem. Soc. 1980, 127, 1489. doi:10.1149/1.2129936

29. Papouchado, L.; Petrie, G.; Adams, R. N. J. Electroanal. Chem. Interfacial Electrochem. 1972, 38, 389 doi:10.1016/S0022-0728(72)80349-8

30. Burke, S. A.; Jones, M. R.; Lee, B. P.; Messersmith, P. B. Biomed. Mater. 2007, 2, 203. doi:10.1088/1748-6041/2/4/001

31. Holowka, E. P.; Deming, T. J. Macromol. Biosci. 2010, 10, 496 doi:10.1002/mabi.200900390

32. Hong, S.; Na, Y. S.; Choi, S.; Song, I. T.; Kim, W. Y.; Lee, H. Adv. Funct. Mater. 2012, 22, 4711. doi:10.1002/adfm.201201156

\section{License and Terms}

This is an Open Access article under the terms of the Creative Commons Attribution License

(http://creativecommons.org/licenses/by/2.0), which permits unrestricted use, distribution, and reproduction in any medium, provided the original work is properly cited.

The license is subject to the Beilstein Journal of Nanotechnology terms and conditions:

(http://www.beilstein-journals.org/bjnano)

The definitive version of this article is the electronic one which can be found at:

doi:10.3762/bjnano.5.101 